\title{
Environmental Policy and Optimal Taxation in a Decentralized Economic Federation*
}

\author{
Thomas Aronsson, Thomas Jonsson and Tomas Sjögren \\ Department of Economics, Umeå University \\ SE - 90187 Umeå, Sweden
}

January 2006

\begin{abstract}
This paper deals with environmental policy in an economic federation, where each national government faces a mixed tax problem. We assume that the federal government sets emission targets, which are implemented at the national level. We also assume that the economic federation is decentralized, meaning that the national governments are first movers vis-a-vis the federal government. Our results show that each country uses it policy instruments, at least in part, to influence the emission target. This has several implications; first, the commodity taxes do not satisfy the so called additivity property often
\end{abstract}

*The authors would like to thank Laurent Simula for helpful comments and suggestions as well as thank the other participants in the HECER workshop on fiscal federalism in Helsinki held at November 18-19, 2005. A research grant from FORMAS is also gratefully acknowledged. 
emphasized in earlier literature and, second, it provides an argument for using distortionary labor income taxation.

Keywords: Income and commodity taxation, economic federation, environmental policy.

JEL classification: D62, H21, H70

\section{Introduction}

A considerable amount of research effort has been put into studying so called transboundary environmental problems. Transboundary environmental damage means that the emissions generated by each country do not only affect the welfare of domestic residents; they also affect the welfare of residents in other jurisdictions. To deal with such resource allocation problems, some kind of cooperation is generally required. This is so because, in the absence of cooperation, part of the external effects of environmental damage may remain uninternalized, since country-specific objectives can be expected to govern the policies decided upon by national governments. Clearly, the ideas behind policy coordination have gained much attention also among policymakers: an indication is the existence of several international arrangements ranging from voluntary agreements between politically independent countries, such as the Kyoto protocol, to arrangements within given institutional structures, such as the environmental policy cooperation within the European Union (EU).

This paper analyzes environmental policy as part of an optimal tax problem facing the member states of an economic federation, which will be designed to reflect some of the characteristics of environmental policy cooperation within the EU. There are (at least) three interesting features that we 
would like to address. First, the federal level - to be called 'federal government' in what follows - is weak relative to the lower level (national) governments $^{1}$; at least in comparison with other economic federations such as the U.S. This is so because the EU is still in the process of being developed, and the member states may already have precommitted themselves to policies based on their own objectives. In addition, the federal government has limited possibilities of rewarding and/or punishing individual member states for their performance in controlling the transboundary parts of their environmental damage. We will interpret this characteristic to mean that the national governments act as first movers vis-a-vis the federal government. Second, the federal government typically decides upon environmental targets for the members countries, which are implemented at the national level ${ }^{2}$. For instance, the EU decides upon targets with regards to different types of water and air pollutants ${ }^{3}$, which are to be implemented at the national level. In addition, although the rules governing these targets might be the same for all countries involved, differences in the production structure or other characteristics may, nevertheless, imply that the effective targets differ across countries. Similarly, the Burden-Sharing Agreement within the EU ${ }^{4}$,

\footnotetext{
${ }^{1}$ Admittedly, without a proper constitution, European federalism is still in its infancy, and the decision-process may also, at least to some extent, resemble negotiations between politically independent countries. In the political science and political geography literature, the decision-making structure of the EU has been described as 'multi-level governance' based on a state-centrist setting. Jones and Clark (2001, page 2) argue that "from this perspective, national governments are the main channels of communication between the EU member states, thereby controlling the overall direction and pace of EU decision-making".

${ }^{2}$ See Wallace and Wallace (1997) for a survey of policy-making within the EU.

${ }^{3}$ See e.g. the Commission of The European Communities (2004).

${ }^{4}$ Details concerning the Burden Sharing Agreement can be found in the Commission
} 
which refers to the distribution of the $\mathrm{CO}_{2}$ reduction target for Europe, was decided upon at the federal (EU) level, and the resulting national emission targets will be implemented by policies decided upon by each national government. Third, if the lower level of government is described as being the first mover, it follows that the lower level governments may, in part, use their policy instruments in order to influence the emission targets. Each of these characteristics is part of the model described below. The main purpose of our paper is to understand what these characteristics imply in the context of optimal taxation at the national level.

Earlier research on environmental policy in economies with transboundary environmental problems deals with the formation of coalitions as well as the use of policy instruments to reach common objectives in such coalitions. One body of literature deals primarily with game theoretic aspects of policy cooperation, in which the incentives underlying the establishment of coalitions is addressed ${ }^{5}$. Earlier studies in this area do not pay so much attention to the question of how to implement a cooperative (or other) arrangement via economic policy in the context of decentralized economies. Another body of literature deals explicitly with implementation of such arrangements by applying theories of optimal taxation or theories of policy reform to multicountry model economies ${ }^{6}$. However, although we have gained much insight of the European Communities (2000). See also Marklund and Samakovlis (2003) for an empirical analysis of the incentives underlying the agreement.

${ }^{5}$ See e.g. Mäler (1989), Barrett (1994) and Carraro (2003).

${ }^{6}$ See e.g. van der Ploeg and de Zeeuw (1992), Aronsson and Löfgren (2000), Aronsson and Blomquist (2003) and Aronsson et al. (2004). In the first two studies, the only task for the government is externality-correction. Aronsson and Blomquist combine externalitycorrection with redistribution, whereas Aronsson et al. analyze how the welfare effects of coordinated environmental policy reforms depend on the characteristics of the prereform equilibrium. 
from earlier research, it has not (in our view) paid sufficient attention to the institutional structure. The welfare effects of public policies, as well as attempts to coordinate policies between jurisdictions, cannot be thoroughly analyzed, if one does not consider the institutional structure in which this policy will be carried out. In many cases, earlier research just implies comparisons between a noncooperative equilibrium, where individual countries and/or regions form their policies in isolation, with a cooperative equilibrium. None of these two extreme cases provide a realistic description of the decision structure underlying many practical environmental policy problems, where the outcome often reflects a mixture of national and international policies.

To our knowledge, there are very few earlier studies dealing with environmental policies in the context of a decentralized economic federation with spillover effects (across lower level jurisdictions) of environmental damage. Silva and Caplan (1997) and Caplan and Silva (1999) analyze different kinds of transboundary environmental problems and associated policies to solve them. These authors consider federal decision-structures, involving a federal government and lower level (e.g. national or regional) governments; the federal government is assumed to control one specific policy instrument (e.g. abatement), whereas the lower level of government is assumed to control another (e.g. environmental taxes). In addition, the economic federation may either be centralized or decentralized, depending on which level is able to make credible commitments (and they use the EU to exemplify a decentralized economic federation $)^{7}$. In their studies, a major purpose seems to be to characterize the environmental policy outcomes on the basis of (i) whether the economic federation is centralized or decentralized, and (ii) how

\footnotetext{
${ }^{7}$ See also the related work on public goods by Caplan et al. (2000) and on tax competition by Köthenburger (2004).
} 
the control over policy instruments is distributed between the two levels of government.

Our study differs from the papers discussed in the preceding paragraph in several ways. First, we do not consider situations where the control of traditional policy instruments is divided between the two levels of government; we assume, instead, that the targets decided upon by the federal government are implemented by policies decided upon by the lower level governments. Second, since our paper is related to the literature on optimal nonlinear taxation in economies in environmental damage, it also differs from the earlier studies in terms of tax instruments. In our paper, the economic federation consists of two lower level jurisdictions ${ }^{8}$, which will be referred to as 'countries', and the policy problem facing the government in each such country is a mixed tax problem, where the set of tax instruments contains a nonlinear income tax and linear commodity taxes. This is a reasonably realistic description of the tax structure characterizing many countries. In addition, it means that the use of distortionary taxation is a consequence of optimization; it is not a consequence of restrictions imposed on the policy instruments. We assume that the aggregate consumption of a particular commodity in each country gives rise to an external effect which, in turn, spills over into the other country. As such, the model bears some resemblance to the models used in earlier literature on optimal income and commodity taxation under environmental damage, such as Pirttilä and Tuomala (1997) and Aronsson and Blomquist (2003), although these earlier studies did not address the federation structure discussed here.

However, instead of analyzing redistribution as part of the policy package, as in some of the aforementioned papers, we follow Fuest and Huber (1997)

\footnotetext{
${ }^{8}$ Adding additional lower level jurisdictions does not affect the qualitative results.
} 
and Aronsson and Sjögren (2004a, 2004b) by disregarding motives for using distortionary taxes that apply under perfect competition (such as asymmetric information). Therefore, the presence of market failures constitutes the only reason for using distortionary taxes in our paper. This does not reflect a belief that other motives for using distortionary taxes are unimportant; only that they are well understood from earlier research. As such, this simplification enables us to concentrate on how the decentralized federal decision-structure contributes to the use of income and commodity taxation at the national level ${ }^{9}$.

The outline of the paper is as follows. In section 2, we describe the model and the outcome of private optimization. The federal decision-structure, dealing with the policy problems facing the federal government and the lower level governments, is introduced in section 3. Much attention is paid to the optimal tax problems facing the lower level governments; a focus which makes it possible to compare our results with those derived in earlier studies on environmental policy in the context of optimal income and commodity taxation. In section 4 , we extend the analysis by relaxing one of the simplifying separability assumptions on which the model is based. Section 5 summarizes the results.

\section{The Model}

Consider an economic federation comprising two separate jurisdictions, denoted by subindices $j=1,2$, each of which will be referred to as a 'country'. The consumers in each such country are identical, and their number will

\footnotetext{
${ }^{9}$ The mechanisms behind the tax structure discussed in this paper would, of course, also be present in a more general framework with redistribution under asymmetric information.
} 
be normalized to one for notational convenience. Consumer preferences in country $j$ are represented by the utility function

$$
u_{j}=a_{j}\left(c_{j}, x_{j}, z_{j}\right)+\phi_{j}^{j}\left(E_{j}\right)+\phi_{j}^{k}\left(E_{k}\right)
$$

for $k \neq j$, where $c$ will be referred to as a 'clean' good and $x$ a 'dirty' good, whereas $z$ is leisure. We assume that $c$ and $x$ are normal goods. Leisure is, in turn, defined as a time endowment, $H$, less the time spent in market work, $l$. The function $a_{j}(\cdot)$ is increasing in each argument and strictly quasi-concave. In addition, the consumption of the dirty good causes environmental damage, $E$, meaning that $x_{j}=E_{j}$ and $x_{k}=E_{k}$. The functions $\phi_{j}^{j}(\cdot)$ and $\phi_{j}^{k}(\cdot)$ are decreasing and strictly concave in their respective argument. The assumption that the external effects enter in a separable way is made for convenience; we will return to some of the implications of this assumption in section 4 . We also assume that the consumer in country $j$ treats $E_{j}$ and $E_{k}$ as exogenous during optimization.

The budget constraint facing the consumer is given by

$$
w_{j} l_{j}-T_{j}\left(w_{j} l_{j}\right)-q_{j, c} c_{j}-q_{j, x} x_{j}=0
$$

where $w_{j}$ is the wage rate and $T_{j}(\cdot)$ a general income tax, whereas $q_{j, c}$ and $q_{j, x}$ are the consumer prices. The consumer prices are defined as $q_{j, c}=p_{j, c}+t_{j, c}$ and $q_{j, x}=p_{j, x}+t_{j, x}$, where $p$ denotes producer price and $t$ commodity tax. To simplify the analysis, we follow (much of the) earlier literature on mixed taxation by assuming that the wage rate and producer prices are fixed ${ }^{10}$.

The optimal tax problem to be examined in this paper will be defined in terms of a conditional indirect utility function and conditional demand

\footnotetext{
${ }^{10}$ This assumption is not important for the qualitative results derived below.
} 
functions. Therefore, following Christiansen (1984), it is convenient to solve the consumer's optimization problem in two stages. In the first stage, we maximize the utility conditional on the time spent in market work. This problem is written

$$
\underset{c_{j}, x_{j}}{\operatorname{Max}} a_{j}\left(c_{j}, x_{j}, z_{j}\right)+\phi_{j}^{j}\left(E_{j}\right)+\phi_{j}^{k}\left(E_{k}\right)
$$

s.t.

$$
b_{j}=q_{j, c} c_{j}+q_{j, x} x_{j}
$$

where $b_{j}$ is treated as a fixed income. The solution defines the conditional demand functions

$$
\begin{aligned}
& x_{j}=x_{j}\left(q_{j, c}, q_{j, x}, b_{j}, z_{j}\right) \\
& c_{j}=c_{j}\left(q_{j, c}, q_{j, x}, b_{j}, z_{j}\right)
\end{aligned}
$$

and the conditional indirect utility function

$$
v_{j}=v_{j}\left(q_{j, c}, q_{j, x}, b_{j}, z_{j}, E_{j}, E_{k}\right)
$$

for $j=1,2$, and $k \neq j$.

In the second stage, the time spent in market work is chosen to maximize the conditional indirect utility function subject to $w_{j} l_{j}-T_{j}\left(w_{j} l_{j}\right)-b_{j}=0$. The first order condition is written

$$
\frac{\partial v_{j}}{\partial b_{j}} w_{j}\left(1-T_{j}^{\prime}\left(w_{j} l_{j}\right)\right)-\frac{\partial v_{j}}{\partial z_{j}}=0
$$

where $T_{j}^{\prime}\left(w_{j} l_{j}\right)=\partial T_{j}\left(w_{j} l_{j}\right) / \partial\left(w_{j} l_{j}\right)$ is the marginal income tax rate. This is the standard labor supply condition and needs no further interpretation. 


\section{A Decentralized Economic Federation}

As we mentioned in the introduction, earlier literature dealing with economic policy in a multi-jurisdictional setting with transboundary environmental problems typically compare a noncooperative Nash equilibrium with a cooperative equilibrium (where the resource allocation is decided upon by a global social planner). What would happen if we were to analyze these two well known resource allocations within the model set out above? Although the noncooperative Nash equilibrium and the cooperative equilibrium differ with respect to the value the decision-makers attach to the environment (the noncooperative Nash equilibrium only internalizes the domestically created external effect, whereas the cooperative equilibrium fully internalizes the external effects on a global level), they would, nevertheless, share at least two important characteristics with regards to the tax structure. First, the commodity tax structure would obey the so called additivity property. The additivity property, which is due to Sandmo (1975), means that environmental damage leads to an additive term in the tax formula for the externalitygenerating commodity, while it has no direct effect on the tax formulas for other commodities. Second, the marginal income tax rate would equal zero, implying that the income tax would be equivalent to a lump-sum tax.

In this section, we will show that none of these characteristics apply in the context of a decentralized economic federation, where the emission targets are decided upon by the federal government and implemented at the national level. As indicated above, we assume that the national governments are first movers vis-a-vis the federal government. The federal government behaves as a traditional follower with one important exception; to be able to define a target reaction function which is consistent with the first order 
conditions of the private sector, we assume that the federal government sets the emission targets as if it expects the implementation to be carried out via the commodity tax on the dirty good. This will be explained below.

\subsection{The Federal Government}

We assume that the objective function of the central government is the sum of the two country-specific objectives

$$
u=\sum_{j} u_{j}
$$

The constraints ${ }^{11}$ facing the federal government are the behavioral equations of the private sector in each country, which can be summarized by the following equations;

$$
\begin{array}{r}
-\frac{\partial u_{j}}{\partial c_{j}} \frac{q_{j, x}}{q_{j, c}}+\frac{\partial u_{j}}{\partial x_{j}}=0 \\
q_{j, c} c_{j}+q_{j, x} x_{j}-b_{j}=0
\end{array}
$$

together with the restriction

$$
E_{j}-x_{j}=0
$$

for $j=1,2$. Equation (8) represents the first order condition for the commodity mix chosen by the consumer in each country, equation (9) is the private budget constraint, and equation (10) relates the environmental damage to the consumption of the dirty good.

\footnotetext{
${ }^{11}$ In a more general framework, the federal government may also redistribute resources between the countries. We abstract from redistributive policies carried out by the federal government.
} 
Note that, since the federal government is assumed to choose $E_{j}$, while at the same time recognizing equation (10), we cannot use equations (8) and (9) to solve for $c_{j}$ and $x_{j}$ as functions of $q_{j, c}, q_{j, x}, b_{j}$ and $z_{j}$ (as we would normally do when analyzing consumer behavior). Therefore, to be able to formulate the federal government's optimization problem, we must make an additional assumption about the tradeoffs at the federal level. We assume that the federal government expects that each emission target is implemented via commodity the tax on the externality-generating $\operatorname{good}^{12}$; as such, the federal government presupposes that a lower $x_{j}$ must imply an increase in $q_{j, x}$ along the demand curve for the dirty good. We can then use equations (8) and (9) to solve for $q_{j, x}$ and $c_{j}$ as functions of $q_{j, c}, x_{j}, b_{j}$ and $z_{j}$, i.e. $q_{j, x}=\check{q}_{j}\left(q_{j, c}, x_{j}, b_{j}, z_{j}\right)$ and $c_{j}=\check{c}_{j}\left(q_{j, c}, x_{j}, b_{j}, z_{j}\right)$. By using equation (10) to replace $x_{j}$ by $E_{j}$, the objective function of the federal government is written as

$$
\underset{E_{1}, E_{2}}{\operatorname{Max}} \sum_{j=1}^{2}\left[a_{j}\left(\frac{b_{j}-\check{q}_{j}\left(q_{j, c}, E_{j}, b_{j}, z_{j}\right) E_{j}}{q_{j, c}}, E_{j}, z_{j}\right)+\phi_{j}^{j}\left(E_{j}\right)+\phi_{j}^{k}\left(E_{k}\right)\right]
$$

for $k=1,2$, and $k \neq j$. Using the first order conditions, we can derive the target reaction functions

$$
\check{E}_{j}=\rho_{j}\left(q_{j, c}, b_{j}, z_{j}\right)
$$

\footnotetext{
${ }^{12}$ This assumption appears to be realistic for the EU. Although implementation is typically a national decision problem, as indicated above, the Commission seems to support the use of market based environmental policy instruments; see e.g. Communication from the Commission (1997). In the context of our model, this is interpreted to mean that the federal government expects that the implementation will be carried out via the commodity tax on the dirty good instead of via the commodity tax on the clean good or the income tax.
} 
for $j=1,2$, which define the targets for the environmental damage as a function of (some of) the national decision variables. Note also that, since $E_{1}$ and $E_{2}$ are additively separable in terms of the utility functions, the reaction function facing country $j$ will only depend on its own decision variables; not the decision variables of the other country. We will return to this assumption in section 4 .

\subsection{Tax Policy at the National Level}

We assume that the national governments behave as Nash competitors towards each other, meaning that each national government treats the policy variables of the other country as exogenous. The order of decision-making in vertical space was indicated above; each national government behaves as a first mover vis-a-vis the federal government.

By using the conditional demand functions and the conditional indirect utility function defined in section 2, we can write the optimal tax problem facing the goverment is country $j$ as

$$
\underset{l_{j}, b_{j}, t_{j, c}, t_{j, x}, E_{j}}{\operatorname{Max}} v_{j}\left(q_{j, c}, q_{j, x}, b_{j}, z_{j}, E_{j}, E_{k}\right)
$$

s.t.

$$
\begin{gathered}
w_{j} l_{j}-b_{j}+t_{j, c} c_{j}\left(q_{j, c}, q_{j, x}, b_{j}, z_{j}\right)+t_{j, x} x_{j}\left(q_{j, c}, q_{j, x}, b_{j}, z_{j}\right)-\bar{g}_{j}=0 \\
E_{j}-x_{j}\left(q_{j, c}, q_{j, x}, b_{j}, z_{j}\right)=0 \\
\rho_{j}\left(q_{j, c}, b_{j}, z_{j}\right)-E_{j} \geq 0
\end{gathered}
$$

for $k \neq j$, where $\bar{g}_{j}$ represents an exogenous revenue requirement. The first constraint is the budget constraint, in which we have used $T_{j}\left(w_{j} l_{j}\right)=w_{j} l_{j}-$ $b_{j}$, whereas the second refers to the relationship between the environmental 
damage generated by country $j$ and the consumption of the dirty good by its resident. These two constraints take the same general form as in earlier studies. The third constraint, on the other hand, is specific to the federal decision structure discussed here. It means that the environmental damage generated by country $j$ must not exceed the target imposed on country $j$ by the federal government, and the assumption that the national government acts as a first mover vis-a-vis the federal government implies, in turn, that it can affect the target, $\rho_{j}(\cdot)$, via some of its policy instruments.

The Lagrangean is written

$$
\begin{aligned}
L_{j}= & v_{j}(\cdot)+\gamma_{j}\left[w_{j} l_{j}-b_{j}+t_{j, c} c_{j}(\cdot)+t_{j, x} x_{j}(\cdot)-\bar{g}_{j}\right]+\mu_{j}\left[E_{j}-x_{j}(\cdot)\right] \\
& +\lambda_{j}\left[\rho_{j}(\cdot)-E_{j}\right]
\end{aligned}
$$

where $\gamma_{j}, \mu_{j}$ and $\lambda_{j}$ are Lagrange multipliers, while the functions $v_{j}(\cdot), c_{j}(\cdot)$, $x_{j}(\cdot)$ and $\rho_{j}(\cdot)$ were defined above. If we concentrate on the case with a binding emission target constraint ${ }^{13}$, the first order conditions become

$$
\begin{array}{r}
l_{j}:-\frac{\partial v_{j}}{\partial z_{j}}+\gamma_{j}\left[w_{j}-t_{j, c} \frac{\partial c_{j}}{\partial z_{j}}-t_{j, x} \frac{\partial x_{j}}{\partial z_{j}}\right]+\mu_{j} \frac{\partial x_{j}}{\partial z_{j}}-\lambda_{j} \frac{\partial \rho_{j}}{\partial z_{j}}=0 \\
b_{j}: \frac{\partial v_{j}}{\partial b_{j}}+\gamma_{j}\left[-1+t_{j, c} \frac{\partial c_{j}}{\partial b_{j}}+t_{j, x} \frac{\partial x_{j}}{\partial b_{j}}\right]-\mu_{j} \frac{\partial x_{j}}{\partial b_{j}}+\lambda_{j} \frac{\partial \rho_{j}}{\partial b_{j}}=0 \\
t_{j, c}:-c_{j} \frac{\partial v_{j}}{\partial b_{j}}+\gamma_{j}\left[c_{j}+t_{j, c} \frac{\partial c_{j}}{\partial q_{j, c}}+t_{j, x} \frac{\partial x_{j}}{\partial q_{j, c}}\right]-\mu_{j} \frac{\partial x_{j}}{\partial q_{j, c}}+\lambda_{j} \frac{\partial \rho_{j}}{\partial q_{j, c}}=0
\end{array}
$$

\footnotetext{
${ }^{13}$ If the emission target constraint does not bind, then the resource allocation will be equivalent to the noncooperative Nash equilibrium that would follow in the absence of a federal decision-structure.
} 


$$
\begin{gathered}
t_{j, x}:-x_{j} \frac{\partial v_{j}}{\partial b_{j}}+\gamma_{j}\left[t_{j, c} \frac{\partial c_{j}}{\partial q_{j, x}}+x_{j}+t_{j, x} \frac{\partial x_{j}}{\partial q_{j, x}}\right]-\mu_{j} \frac{\partial x_{j}}{\partial q_{j, x}}=0 \\
E_{j}: \frac{\partial v_{j}}{\partial E_{j}}+\mu_{j}-\lambda_{j}=0
\end{gathered}
$$

in which we have used the time constraint, $z=H-l$, to derive equation (13) and Roy's identity to write the first order conditions for $t_{j, c}$ and $t_{j, x}$ in the form of equations (15) and (16), respectively. Note also that the form of equation (17) is due to the assumption that $E_{j}$ is additively separable in terms of the utility function. We will now analyze equations (13)-(17) from the perspective of their implications for the tax structure.

\subsection{The Shadow Price of the Environment}

As in earlier literature, the shadow price of environmental damage over the shadow price of the government's budget constraint, $\mu_{j} / \gamma_{j}$, is an important part of the optimal tax structure. This ratio of shadow prices is interpretable to measure the value that the government in country $j$ attaches to reduced domestic environmental damage. Let $M W P_{j}^{E_{j}, b_{j}}=-\left(\partial v_{j} / \partial E_{j}\right) /\left(\partial v_{j} / \partial b_{j}\right)$ denote the marginal willingness to pay by the resident in country $j$ for a small reduction in $E_{j}$, whereas $\tilde{c}_{j}$ and $\tilde{x}_{j}$ denote the compensated demand functions. To derive an expression for $\mu_{j} / \gamma_{j}$, we will use equations (14) and (17) along with the Slutsky type formulas

$$
\begin{aligned}
\frac{\partial \tilde{c}_{j}}{\partial E_{j}} & =\frac{\partial c_{j}}{\partial E_{j}}+\frac{\partial c_{j}}{\partial b_{j}} M W P_{j}^{E_{j}, b_{j}} \text { and } \\
\frac{\partial \tilde{x}_{j}}{\partial E_{j}} & =\frac{\partial x_{j}}{\partial E_{j}}+\frac{\partial x_{j}}{\partial b_{j}} M W P_{j}^{E_{j}, b_{j}}
\end{aligned}
$$

Our result is summarized by Proposition 1; 
Proposition 1 In the context of the decentralized economic federation, the shadow price of the domestic environmental damage over the shadow price of the government's budget constraint can be written as

$$
\frac{\mu_{j}}{\gamma_{j}}=\frac{1}{\sigma_{j}}\left[M W P_{j}^{E_{j}, b_{j}}-\left\{t_{j, c} \frac{\partial \tilde{c}_{j}}{\partial E_{j}}+t_{j, x} \frac{\partial \tilde{x}_{j}}{\partial E_{j}}\right\}+\frac{\lambda_{j}}{\gamma_{j}}\left(1-\frac{\partial \rho_{j}}{\partial b_{j}} M W P_{j}^{E_{j}, b_{j}}\right)\right]
$$

where $\sigma_{j}=1-\partial \tilde{x}_{j} / \partial E_{j}$.

The first part of the formula in Proposition 1 is the marginal willingness to pay by the consumer for a reduction of the environmental damage, whereas the second part represents tax base effects of environmental damage associated with the commodity taxes. Note that the tax base effects are defined in terms of the compensated demand functions. The reason is that the income tax is optimally chosen; a change in the revenues from commodity taxation will, therefore, be complemented by a corresponding change in the income tax to retain budget balance. These effects are well understood from earlier research. On the other hand, the third part on the right hand side (which is proportional to $\lambda_{j} / \gamma_{j}$ ) is novel. This effect is associated with the environmental target decided upon by the federal government, which is also the reason why the formula in Proposition 1 differs from the corresponding expression derived in the context of a noncooperative Nash equilibrium without a federal government ${ }^{14}$.

For purposes of interpretation, let us assume that $\lambda_{j} / \gamma_{j}>0$, which appears to be natural considering that a relaxation of the target (if it is binding) is likely to increase the welfare level from the perspective of country $j$.

\footnotetext{
${ }^{14}$ See Aronsson and Blomquist (2003). In their study, $\mu_{j} / \gamma_{j}$ is also affected by a selfselection constraint, since they consider redistribution under asymmetric information as being part of the decision problem facing each national government. See also the corresponding optimal tax problem for a one-country model economy addressed by Pirttilä and Tuomala (1997).
} 
Then, notice that the third part of the shadow price formula in Proposition 1 can be decomposed into two separate effects; a direct effect of $E_{j}$ on the target-related constraint facing the national government (which is defined conditional on the target function, $\left.\rho_{j}(\cdot)\right)$ and an indirect effect on the target function via one of the decision variables facing the national government. The direct effect works to increase $\mu_{j} / \gamma_{j}$; it means that the national government is forced to attach a higher value on the environment than it would otherwise have done. As we will see below, this effect works to increase the commodity tax on the dirty good. The indirect effect appears because the national government is a first mover vis-a-vis the federal government. If an increase in the private income relaxes (tightens) the target, so $\partial \rho_{j} / \partial b_{j}>0$ $(<0)$, there is an incentive for the national government to choose a lower (higher) income tax payment for the consumer than it would otherwise have done. This is interpretable as an extra cost (benefit) associated with raising tax revenues, which works to increase (decrease) the marginal cost of public funds in utility terms. As such, it contributes to decrease (increase) $\mu_{j} / \gamma_{j}$. Therefore, the possibility to influence the environmental target may have important implications for the value attached to the environment by the government.

\subsection{Commodity Taxation}

The commodity tax structure is defined by equations (15) and (16). Since we will discuss the role of commodity taxation in the context of an optimal tax structure, in which the income tax is also optimally chosen, we substitute equation (14) into equations (15) and (16). Then, by using the Slutsky condition, equations (15) and (16) can be rewritten as 


$$
\left[\begin{array}{cc}
\frac{\partial \tilde{c}_{j}}{\partial q_{j, c}} & \frac{\partial \tilde{x}_{j}}{\partial q_{j, c}} \\
\frac{\partial \tilde{c}_{j}}{\partial q_{j, x}} & \frac{\partial \tilde{x}_{j}}{\partial q_{j, x}}
\end{array}\right] \times\left[\begin{array}{c}
t_{j, c} \\
t_{j, x}
\end{array}\right]=\left[\begin{array}{c}
\frac{\mu_{j}}{\gamma_{j}} \frac{\partial \tilde{x}_{j}}{\partial q_{j, c}}-\frac{\lambda_{j}}{\gamma_{j}}\left(\frac{\partial \rho_{j}}{\partial q_{j, c}}+\frac{\partial \rho_{j}}{\partial b_{j}} c_{j}\right) \\
\frac{\mu_{j}}{\gamma_{j}} \frac{\partial \tilde{x}_{j}}{\partial q_{j, x}}-\frac{\lambda_{j}}{\gamma_{j}} \frac{\partial \rho_{j}}{\partial b_{j}} x_{j}
\end{array}\right]
$$

where the determinant of the matrix at the left hand side becomes

$$
\left|H_{j}\right|=\frac{\partial \tilde{c}_{j}}{\partial q_{j, c}} \frac{\partial \tilde{x}_{j}}{\partial q_{j, x}}-\frac{\partial \tilde{c}_{j}}{\partial q_{j, x}} \frac{\partial \tilde{x}_{j}}{\partial q_{j, c}}>0
$$

By applying Cramer's rule on equation system (18), we can derive expressions for the optimal commodity taxes (on an implicit form). Consider Proposition 2;

Proposition 2 In the context of the decentralized economic federation, the commodity tax structure is characterized by

$$
\begin{gathered}
t_{j, c}=\frac{\lambda_{j}}{\gamma_{j}} \frac{1}{\left|H_{j}\right|}\left[-\frac{\partial \tilde{x}_{j}}{\partial q_{j, x}} \frac{\partial \rho_{j}}{\partial q_{j, c}}+\frac{\partial \tilde{x}_{j}}{\partial q_{j, x}} \frac{\partial \rho_{j}}{\partial b_{j}}\left(\frac{\partial \tilde{x}_{j} / \partial q_{j, c}}{\partial \tilde{x}_{j} / \partial q_{j, x}} x_{j}-c_{j}\right)\right] \\
t_{j, x}=\frac{\mu_{j}}{\gamma_{j}}+\frac{\lambda_{j}}{\gamma_{j}} \frac{1}{\left|H_{j}\right|}\left[\frac{\partial \tilde{c}_{j}}{\partial q_{j, x}} \frac{\partial \rho_{j}}{\partial q_{j, c}}+\frac{\partial \tilde{c}_{j}}{\partial q_{j, c}} \frac{\partial \rho_{j}}{\partial b_{j}}\left(\frac{\partial \tilde{c}_{j} / \partial q_{j, x}}{\partial \tilde{c}_{j} / \partial q_{j, c}} c_{j}-x_{j}\right)\right]
\end{gathered}
$$

To interpret Proposition 2, consider first the special case without a federal decision-structure, meaning that $\rho_{j}(\cdot) \equiv 0$. In this case, we obtain a standard result; $t_{j, c}=0$ and $t_{j, x}=\mu_{j} / \gamma_{j}$, which satisfies the additivity property. However, for our more general model, it is clear that the commodity tax structure does no longer satisfy the additivity property; at least not if we recognize that the policy instruments are, in part, used to influence the environmental target decided upon by the federal government. Therefore, although the real shadow price of environmental damage facing the government, $\mu_{j} / \gamma_{j}$, only appears in the tax formula for the dirty good, while it has no direct effect on the tax formula for the clean good, each tax formula also contains expressions that are proportional to $\lambda_{j} / \gamma_{j}$. As such, these terms 
reflect that the national government uses income and commodity taxation to affect the environmental target. The basic intuition behind this lack of additivity is that the national government has fewer policy instruments at its disposal than it has variables to control.

Since the pure externality-part of the tax formula for the dirty good, $\mu_{j} / \gamma_{j}$, is well understood from earlier research, we concentrate the discussion on the other components of the tax structure, all of which are due to the desire to relax the emission target. Furthermore, we assume that $\lambda_{j} / \gamma_{j}>0$, which is in accordance with our earlier discussions. Consider first the formula for the commodity tax on the clean good, $t_{j, c}$. The first term within the bracket reflects the direct effect of $t_{j, c}$ on the environmental target. Since $\partial \tilde{x}_{j} / \partial q_{j, x}<0$, it follows that $\partial \rho_{j} / \partial q_{j, c}>0(<0)$ provides an incentive for the government to choose a higher (lower) $t_{j, c}$ than it would otherwise have done. The intuition is, of course, that this adjustment contributes to relax the emission target.

The second part of the expression within the bracket in the formula for $t_{j, c}$

$$
\frac{\partial \tilde{x}_{j}}{\partial q_{j, x}} \frac{\partial \rho_{j}}{\partial b_{j}}\left(\frac{\partial \tilde{x}_{j} / \partial q_{j, c}}{\partial \tilde{x}_{j} / \partial q_{j, x}} x_{j}-c_{j}\right),
$$

is due to budget balance arguments; a change in the commodity tax structure may necessitate an adjustment of the income tax which, in turn, influences the environmental target. This part is decomposable into two separate effects. One is a direct budget balance effect (the terms proportional to $c_{j}$ ). If $\partial \rho_{j} / \partial b_{j}>0(<0)$, then a lower (higher) income tax payment contributes to relax the emission target. Given the revenue requirement, this constitutes an incentive to adjust the commodity tax structure by increasing (decreasing) $t_{j, c}$, ceteris paribus. The other part of the budget balance effect arises be- 
cause $c_{j}$ and $x_{j}$ are nonseparable in terms of the utility function; as such, it may either reinforce or counteract the direct budget balance effect discussed before. To understand why nonseparability between goods constitutes additional information of importance for the commodity tax structure, recall that the use of $t_{j, c}$ in this model is due solely to the desire to affect the emission target; there is no reason to use $t_{j, c}$ in order to directly distort the consumption of the dirty good. Therefore, if $\partial \tilde{x}_{j} / \partial q_{j, c} \neq 0$, there is an incentive to adjust $t_{j, x}$ accordingly, so as to keep $\tilde{x}_{j}$ constant. The direction and strength of this effect are, in turn, dependent upon how the income tax affects the emission target. Let

$$
\left.d t_{j, x}\right|_{\tilde{x}_{j}=\bar{x}_{j}}=-\frac{\partial \tilde{x}_{j} / \partial q_{j, c}}{\partial \tilde{x}_{j} / \partial q_{j, x}} d t_{j, c}
$$

be the be the induced change in $t_{j, x}$, which is required to keep $\tilde{x}_{j}$ constant (equal to $\bar{x}_{j}$ ) as $t_{j, c}$ increases marginally. Consider first the case where the commodities are complements, so $\left.d t_{j, x}\right|_{\tilde{x}_{j}=\bar{x}_{j}}<0$, indicating that a marginal increase in $t_{j, c}$ must be accompanied by a decrease in $t_{j, x}$ in order to keep $\tilde{x}_{j}$ constant. As can be seen from the formula for the commodity tax on the clean good, if $\partial \rho_{j} / \partial b_{j}>0(<0)$, then this effect constitutes an incentive for the government to choose a lower (higher) tax on the clean good than it would otherwise have done. The intuition is that the increased income tax payment following the induced reduction of $t_{j, x}$ tightens (relaxes) the emission target, which the government wants to avoid (accomplish). The intuition goes the other way around if the two goods are substitutes, in which case $\left.d t_{j, x}\right|_{\tilde{x}_{j}=\bar{x}_{j}}>0$.

Turning to the tax formula for the dirty good, notice first that the so called budget balance effects - summarized by the second part of the expression within the bracket - are analogous to, and have the same interpretations 
as, the corresponding terms in the tax formula for the clean good, which were discussed at some length above. Therefore, we concentrate our interpretations to the first term within the bracket. To understand this part of the tax formula, it is necessary to bear in mind that $t_{j, c}$ directly affects the emission target, whereas $t_{j, x}$ does not; a result due to the assumptions underlying the optimization problem of the federal government. This explains the asymmetry between the tax formulas; the tax formula for the clean good contains a direct effect of $q_{j, c}$ on the emission target, whereas the tax formula for the dirty good does not (for obvious reasons) contain a corresponding direct effect of $q_{j, x}$ on the target. To provide some intuition, let us rewrite the first part of the expression within the bracket in the formula for $t_{j, x}$ to read

$$
\frac{\partial \tilde{c}_{j}}{\partial q_{j, c}} \frac{\partial \rho_{j}}{\partial q_{j, c}} \frac{\partial \tilde{c}_{j} / \partial q_{j, x}}{\partial \tilde{c}_{j} / \partial q_{j, c}}
$$

where $\partial \tilde{c}_{j} / \partial q_{j, c}<0$. Then, by observing that the government has no reason to use $t_{j, x}$ for the explicit purpose of distorting the clean good, it becomes convenient to define

$$
\left.d t_{j, c}\right|_{\tilde{c}_{j}=\bar{c}_{j}}=-\left[\left(\partial \tilde{c}_{j} / \partial q_{j, x}\right) /\left(\partial \tilde{c}_{j} / \partial q_{j, c}\right)\right] d t_{j, x}
$$

to be the change in $t_{j, c}$ required to keep $\tilde{c}_{j}$ constant (equal to $\bar{c}_{j}$ ) as $t_{j, x}$ increases marginally. Suppose first that $\partial \rho_{j} / \partial q_{j, c}>0$, implying that an increase in the tax on the clean good relaxes the emission target. Then, if the two goods are complements (substitutes), so $\left.d t_{j, c}\right|_{\tilde{c}_{j}=\bar{c}_{j}}<0(>0)$, then there is an incentive to choose a lower (higher) commodity tax on the dirty good than otherwise. The reason is, of course, that the government attempts to relax the emission target via the induced change in the commodity tax for the clean good. Instead, suppose that $\partial \rho_{j} / \partial q_{j, c}<0$, in which case a higher tax on the clean good tends to tighten the target. This situation means 
that if two goods are complements (substitutes), so $\left.d t_{j, c}\right|_{\tilde{c}_{j}=\bar{c}_{j}}<0(>0)$, then there is an incentive to choose a higher (lower) commodity tax on the dirty good, since the induced reduction (increase) in $t_{j, c}$ relaxes the emission target.

\subsection{Income Taxation}

We argued in the beginning of section 3 that, if our framework is used in the context of traditional models of noncooperative Nash behavior and cooperative behavior, then the marginal income tax rate will be equal to zero (recall that we abstract from asymmetric information). As a consequence, the income tax would be equivalent to a lump-sum tax. However, this result does no longer apply in the decentralized economic federation. Consider Proposition 3;

Proposition 3 In the decentralized economic federation, the marginal income tax rate is characterized by

$$
T_{j}^{\prime}\left(w_{j} l_{j}\right)=\frac{1}{w_{j}}\left[t_{j, c} \frac{\partial \tilde{c}_{j}}{\partial z_{j}}+\left(t_{j, x}-\frac{\mu_{j}}{\gamma_{j}}\right) \frac{\partial \tilde{x}_{j}}{\partial z_{j}}+\frac{\lambda_{j}}{\gamma_{j}}\left(\frac{\partial \rho_{j}}{\partial z_{j}}-\frac{\partial \rho_{j}}{\partial b_{j}} \frac{\partial v_{j} / \partial z_{j}}{\partial v_{j} / \partial b_{j}}\right)\right]
$$

where $t_{j, c}$ and $t_{j, x}$ are defined in Proposition 2.

Notice first that the tax structure of traditional models appears as a special case of the more general model analyzed here. This is so because, if $t_{j, c}=0, t_{j, x}=\mu_{j} / \gamma_{j}$ and $\rho_{j}(\cdot) \equiv 0$, then it must also hold that $T_{j}^{\prime}\left(w_{j} l_{j}\right)=0$.

Turning to the more general expression for the marginal income tax rate in Proposition 3, recall from the commodity tax formulas in Proposition 2 that the direct externality-correcting component, $\mu_{j} / \gamma_{j}$, enters additively in the formula for $t_{j, x}$, whereas it does not directly affect the formula for $t_{j, c}$. 
It follows from the second term on the right hand side of the expression in Proposition 3 that the use of distortionary income taxation is not associated with externality-correction per se. Instead, in our model, a nonzero marginal income tax rate will reflect a combination of two motives; (i) the desire to offset distortions due to commodity taxation and (ii) the desire to relax the emission target. This is intuitively reasonable, as we have fewer effective policy instruments than variables to control.

The first two terms on the right hand side, which are proportional to $t_{j, c}$ and $t_{j, x}-\mu_{j} / \gamma_{j}$, respectively, are associated with the former motive for using labor income taxation. As we saw in Proposition 2, the formulas for $t_{j, c}$ and $t_{j, x}-\mu_{j} / \gamma_{j}$ should be designed to relax the emission target. At the same time, the higher each such tax, the more it may distort consumption (as represented by the compensated demand functions), which provides an incentive to adjust the marginal income tax rate accordningly. For instance, the higher $t_{j, c}$ at the second best optimum, ceteris paribus, the higher (lower) will be the marginal income tax rate, if leisure is complementary with (substitutable for) the clean good in the sense that $\partial \tilde{c}_{j} / \partial z_{j}>0(<0)$. The intuition is that a higher (lower) marginal income tax rate contributes to decrease (increase) the hours of work. The term proportional to $t_{j, x}-\mu_{j} / \gamma_{j}$ can be given an analogous interpretation is terms of complementarity or substitutability between the dirty good and leisure.

The third term on the right hand side is due to the desire to relax the emission target. As such, it is decomposable into two parts. First, if more use of leisure contributes to relax (tighten) the emission target, so $\partial \rho_{j} / \partial z_{j}>0$ $(<0)$, there is an incentive to choose a higher (lower) marginal income tax rate than otherwise. Second, if an increase in the private income relaxes (tightens) the emission target, so $\partial \rho_{j} / \partial b_{j}>0(<0)$, there is an incentive 
for the government to increase (decrease) the private income, which can be accomplished by a lower (higher) marginal income tax rate.

\section{Relaxing Part of the Separability}

In the model set out in section 2 , and analyzed in section 3 , the measures of environmental damage, $E_{j}$ and $E_{k}$, are assumed to be (i) additively separable from the other goods in the utility function and (ii) additively separable from each other. The first assumption is not so important from our perspective; it only means that consumption and hours of work are independent of the environmental damage, and the consequences of this assumption are well understood from earlier literature. The second assumption, on the other hand, may be very important from the point of view of the incentive structure in a decentralized economic federation. Although easily motivated by our desire to concentrate on how each national government may influence its own emission target (which we did in the previous section), the implications of relaxing the second assumption should, at least, be discussed.

Therefore, suppose that we were to rewrite the instantaneous utility function facing the consumer to read

$$
u_{j}=a_{j}\left(c_{j}, x_{j}, z_{j}\right)+\kappa_{j}\left(E_{j}, E_{k}\right)
$$

for $k \neq j$, where $E_{j}$ and $E_{k}$ are assumed to be substitutes. The special case of perfect substitutability (meaning that $E_{j}+E_{k}$ is the argument in the function $\left.\kappa_{j}(\cdot)\right)$ is interpretable as the climate problem associated with greenhouse gas emissions.

In this case, by solving the corresponding optimization problem for the federal government, we obtain the target reaction functions 


$$
\check{E}_{j}=\rho_{j}\left(q_{j, c}, b_{j}, z_{j}, q_{k, c}, b_{k}, z_{k}\right)
$$

for $j=1,2$, and $k \neq j$. This means that each national government is no longer only able to affect its own target; it is also able to affect the target of the other country.

By proceeding in the same way as in the previous section, therefore, it is intuitively clear that an additional constraint ought to be added to the optimization problem of the national government in country $j$; namely $\rho_{k}\left(q_{k, c}, b_{k}, z_{k}, q_{j, c}, b_{j}, z_{j}\right)-E_{k} \geq 0$. This means that the first order conditions for $l_{j}, b_{j}$ and $q_{j, c}$ will contain an additional term, reflecting how each of these variables affects the emission target function of the other country. As a consequence, this information will also be part of the optimal tax structure, implying that additional terms (reflecting how these policy instruments affect the other emission target function) should be added to the income and commodity tax expressions presented above.

Our idea here is not to add technical details; only to argue that with this extension, there would be an additional motive behind the tax policy, which was neglected in the previous section. The point we would like to make here is simply that, if $E_{j}$ and $E_{k}$ are not separable from each other in terms of the utility function, each country does not use its policy instruments just to relax its own target; it also uses these instruments in order to affect the emission target of the other country. We hope to develop these ideas in future research. 


\section{Summary and Discussion}

This paper deals with environmental policy in the context of a mixed tax problem facing each national government in an economic federation. We assume that the federal government chooses emission targets for the countries, which are implemented at the national level. Each national government treats other national governments as Nash competitors. We also assume that the economic federation is decentralized, meaning that the national governments are first movers vis-a-vis the federal government in vertical space. Our model is inspired by the decision-structure underlying the environmental policy within the EU.

The idea behind our study is to characterize the optimal tax structure; it is not to establish whether taxes are higher or lower than in a standard model. As such, we are able to describe why, and how, standard rules for income and commodity taxation are modified. Our results suggest a strategic motive for tax policy not discussed in earlier literature; each country uses its policy instruments, at least in part, to influence the emission target. This has several important implications for the optimal tax structure; first the commodity taxes do not satisfy the so called additivity property often emphasized in earlier literature and, second, it provides an argument for using distortionary labor income taxation.

Clearly, as we indicated in the introduction, European federalism is still in its infancy, meaning that the it may not be entirely clear how the behavior at the 'federal level' ought to be described. At the same time, the basic issue here is that the lower level (national) governments are able to commit to their policies, implying that the 'federal outcome', however defined, is conditioned on the policy variables decided upon at the national level. As long as this 
assumption is relevant, our analysis may shed light on the implications for tax policy at the national level of being able, in part, to affect the targets decided upon by the federal level.

\section{References}

[1] Aronsson, T. and Blomquist, S. (2003) Optimal Taxation, Global Externalities and Labor Mobility. Journal of Public Economics 87, 2749-2764.

[2] Aronsson, T., Jonsson, T. and Sjögren, T. (2004) Environmental Policy Reforms and the Labor Market in a Global Economy. Umeå Economic Studies 629.

[3] Aronsson, T. and Löfgren, K-G. (2001) Green Accounting and Green Taxes in the Global Economy. In Folmer, H., Gabel, L. and Rose, A. (eds) Frontiers of Environmental Economics. Cheltenham: Edward Elgar Publishing Limited.

[4] Aronsson, T. and Sjögren, T. (2004a) Is the Optimal Labor Income Tax Progressive in a Unionized Economy? Scandinavian Journal of Economics 106, 661-675.

[5] Aronsson, T. and Sjögren, T. (2004b) Efficient Taxation, Wage Bargaining and Policy Coordination. Journal of Public Economics 88, 27112725 .

[6] Barrett, S. (1994) Self-Enforcing International Environmental Agreements. Oxford Economic Papers 46, 878-894.

[7] Caplan, A., Cornes, R. and Silva, E. (2000) Pure Public Goods and Income Redistribution in a Federation with Decentralized Leadership 
and Imperfect Labor Mobility. Journal of Public Economics 77, 265284.

[8] Caplan, A. and Silva, E. (1999) Federal Acid Rain Games. Journal of Urban Economics 46, 25-52.

[9] Carraro, C. (Ed.) (2003) The Endogenous Formation of Economic Coalitions. Edward Edgar, Cheltenham

[10] Christiansen, V. (1984) Which Commodity Taxes Should Supplement the Income Tax? Journal of Public Economics 24, 195-220.

[11] Commission of the European Communities (2000) Green paper on greenhouse gas emissions trading within the European Union. COM(2000) 87 final (presented by the Commission)

[12] Commission of the European Communities (2004) Sixth Annual Survey on the Implementation and Enforcement of Comminity Environmental Law. Commission Staff Working Paper.

[13] Communication from the Commission (1997) Environmental Taxes and Charges in the Single Market.

[14] Fuest, C. and Huber, B. (1997) Wage bargaining, Labor-Tax Progression, and Welfare. Journal of Economics 66, 127-150.

[15] Jones, A. and Clark, C. (2001) The Modalities of European Union Governance - New Institutionalist Explanations of Agri-Environmental Policy. Oxford University Press, Oxford.

[16] Köthenburger, M. (2004) Tax Competition in a Fiscal Union with Decentralized Leadership. Journal of Urban Economics 55, 498-513. 
[17] Marklund, P-O. and Samakovlis, E. 2003. What is driving the EU Burden-Sharing Agreement: Efficiency or equity? Umeå Economic Studies 620 .

[18] Mäler, K-G, 1989. The Acid Rain Game. In: Folmer, H., van Jerland, E. (Eds.), Valuation Methods and Policy Making in Environmental Economics. Elsevier, Amsterdam.

[19] van der Ploeg, F. and de Zeeuw, A.J. (1992) International Aspects of Pollution Control. Environmental and Resource Economics 2, 117-139.

[20] Pirttilä, J. and Toumala, M. (1997) Income Tax, Commodity Tax and Environmental Policy. International Tax and Public Finance 4, 379-393.

[21] Sandmo, A., 1975. Optimal Taxation in the Presence of Externalities. Scandinavian Journal of Economics 77, 86-98.

[22] Silva, E. and Caplan, A. (1997) Transboundary Pollution Control in Federal Systems. Journal of Environmental Economics and Management 34, 173-186.

[23] Wallace, H. and Wallace, W. (Eds.) (1997) Policy-Making in the European Union. Oxford University Press, Oxford 